\title{
Sustainable leadership: power of influence in MNCS in Malaysia
}

\author{
May-Chiun Lo ${ }^{\mathrm{a}, *}$, Thurasamy Ramayah ${ }^{\mathrm{b}}$ and Yin Chai Wang ${ }^{\mathrm{c}}$ \\ ${ }^{a}$ Faculty of Economics and Business, Universiti Malaysia Sarawak, Kota \\ Samarahan, Sarawak 94300, Malaysia \\ ${ }^{\mathrm{b}}$ School of Management, Universiti Sains Malaysia, Gelugor, Penang \\ 11900, Malaysia \\ ${ }^{\mathrm{c}}$ Faculty of Computer Science and Information Technology, Universiti \\ Malaysia Sarawak, Kota Samarahan, Sarawak 94300, Malaysia
}

Building upon social exchange theory which explains how power is gained and lost in the process of influence between an agent and the target, this article hypothesized the impact of supervisors' and subordinates' power bases on the usage of influence tactics by the supervisors. Bases of power of supervisors, subordinates and influence tactics were conceptualized as seven-, seven- and nine-dimensional constructs, respectively. Three hundred and eighty-five pairs of Malaysian managers and executives working in large multinational companies participated. Currently, the manufacturing sector is considered as one of the cornerstone of Malaysia's economic diversification strategy. The findings suggested that supervisors apply various influence tactics on their subordinates.

Keywords: position power; personal power; influence tactics; Malaysia; multinational companies

JEL Classification: M00; M10

\section{Introduction}

Leadership is a process of interaction between leaders and subordinates where a leader attempts to influence the behaviour of his or her subordinates to accomplish organizational goals (Yukl, 2010). Leadership cannot take place without the participation of the subordinates and power is the essence of leaders' behaviour.

Lawrence et al. (2005) noted that power has been defined narrowly in the theory of management and scholars have recognized that a wide variety of forms of power can take place in organizations.
Studies in the past on power have illustrated how supervisors gain or lose their power, how different uses of power types contributed to leadership effectiveness and how the influence of behaviour contributes to effective leadership (Covaleski et al., 1998; Fiol et al., 2001; Shen and Cannella, 2002). It is believed that both the supervisors and the subordinates have the ability and tendency to influence one another. As stated by Steizel and Rimbau-Gilabert (2013), effective performance in the organizations cannot do without influence and employees must influence others in order to get things done.

\footnotetext{
*Corresponding author. E-mail: mclo@feb.unimas.my
} 